\title{
Mozaiklerin Yerinde Sergilenmesi ve Korunmasına Yönelik Tasarımlarda İlişkisel Anlam Çözümlemesinin Katkıları
}

\section{Contributions of Relational Meaning Analysis in Designs for the Exposure and Conservation of Mosaics}

\author{
Gözde KIRLI ÖZER*
}

(Received 21 April 2020, accepted after revision 19 August 2021)

$\ddot{\mathrm{O} z}$

Günümüzde yerinde koruma ve sergileme giderek önem kazanmaktadır. Bu durum sergilenen eserin değerini ortaya çıkarırken, en ideal koruma koşullarını sağlayacak mimari ve endüstriyel sergi elemanlarının gerekliliğini de beraberinde getirmiștir. Tasarlanan elemanın işlevsel olduğu kadar görsel olarak da sergilenen kültür varlığının önem ve değerini yansıtı nitelikte olması gerekmektedir. Tasarlanan sergi elemanları, eserleri korurken görmeye gelenlere farklı duyulara hitap eden deneyimler yaşatabildikleri ölçüde başarılı olarak değerlendirilmektedir. Bu başarı eserlerin korunabilme oranı, tasarımın farklı kullanıcıların gereksinimlerine cevap verebilmesi ve ekonomik katkı sağlayabilecek mekânsal niteliklere karşıllk verebilmesiyle ölçülür.

Bu çalışma kapsamında yerinde korunması uygun görülen mozaiklerin korunması ve sergilenmesine yeterli ve nitelikli öneriler getirebilmek için düşünülmesi gereken ilişkiler ve bu ilişkilerin bileşenlerinden bahsedilecek ve tasarım sürecinde göz önünde bulundurulması önemli olan koşulların altı çizilecektir.

Anahtar Kelimeler: Arkeolojik peyzaj, mozaik, koruyucu örtü tasarımı, ilişsisel çözümleme.

\begin{abstract}
Today, on-site preservation and display are gaining more importance. While this situation reveals the value of the exhibited work, it has necessitated architectural and industrial exhibition structures that will provide the ideal protection conditions. The designed element should be functional and visually reflect the importance and value of the cultural heritage exhibited. While preserving the works, the designed exhibition structures are considered successful to the extent that they provide experiences appealing to different senses to those who come to see them. This success is measured by the preservation rate of the artefacts, the design's ability to respond to the needs of different users, and its ability to respond to spatial qualities that can contribute economically.

Within the scope of this study, the relations that need to be considered to make adequate and qualified suggestions for the preservation and display of mosaics that are deemed appropriate to be preserved in situ will be mentioned, and the conditions that are important to be considered in the design process will be underlined.
\end{abstract}

Keywords: Archaeological landscape, mosaic, protective structure design, relationship analysis.

\footnotetext{
* Gözde Kırlı Özer, Bursa Uludağ Üniversitesi, İznik Meslek Yüksek Okulu, Mimarlık ve Şehir Planlama Bölümü, Mimari Restorasyon Programı, Bursa, Türkiye. (DD https://orcid.org/0000-0003-4921-3958. E-mail: gozdekrl@uludag.edu.tr
} 


\section{Giriş}

En özgün anlamlarıyla anıtlar; insanın yaptığı işleri, sahip olduğu hünerleri ve gelecek kuşaklara aktarmayı uygun bulduğu bilgileri iletmek amacıyla inșa ettiği, taşınır ve taşınamaz eserlerdir. Tarihi anıtlar ortaya çıktıkları çevrelerde tarihi süreç içerisinde gelişerek gelen kültürün anlık bir kesitini yansıttıkları için eskilik değerine, geçmişi anlamak ve aydınlatmak için birer araç olduklarından dolayı anımsatma değerine ve ortaya çıktıkları andan itibaren insanoğluna ait birer bilgi kaynağı olduklarından dolayı da kullanım değerine sahiptirler. Anıtların anımsatma değeri, insanın duyusal ve ruhsal ihtiyaçlarını tatmin etme yetisine sahip olması dolayısıyla ortaya çıkar. Bu değer bakımından insan anıtın oluşturulduğu andaki halini deneyimlemeyi ve onun tam bir kapalılığa, doğanın ve insanın yıkıcı etkilerine karşı bir dokunulmazlığa sahip olmasını istemeye yatkındır (Reigl 2015). Bu yatkınlığın sonucu olarak koruma kavramı ortaya çıkmıştır. Koruma yaklaşımlarını taşınabilir kültür varlıklarında uygulamak yerleşimler, yapılar, mozaikler ve duvar resimleri gibi taşınmaz kültür varlıklarına göre görece daha kolaydır. Anıtlardan geriye kalan kalıntıları yerinde, orijinal ortamlarında ve bağlamlarında korumak ve sunmak, değerlerini en üst düzeye çıarmak ve onlardan faydalanmak için en iyi yoldur. Ancak tarihi kalıntılar kendilerini atmosferik koşullardan koruyamaz ve orijinal kabuklarının gevşemesi ve malzemelerinin kırılganlığı nedeniyle yaşlanma faktörlerine karşı savunmasızdırlar (Rizzi 2007). Bu nedenle her ne amaçla üretilmiş olursa olsunlar uzun zaman yer altında kalmış kalıntıların, araştıılmak ve sergilenmek üzere ortaya çıkarıldığı andan itibaren değişen iklimsel ve fiziksel koşullara karşı zarar görmeden korunabilmesi ve üretim amacı olan çeşitli türdeki bilgiyi aktarabilmesi açısından, koruma yöntemlerine başvurmak büyük önem taşımaktadır.

Taşınamaz mirasın korunması son yıllarda birçok uluslararası platformda tartışılmaya başlanmış ve doğal veya insan yapımı unsurları açısından yenilenemeyen karakterleri nedeniyle birçok uluslararası belgenin parçası haline gelmiştir. Uluslararası platformlarda ilk defa 1666 'da İsveç Beyannamesi'nde yer bulan "yerinde koruma" kavramı, Anadolu coğrafyasında Osmanlı İmparatorluğu'nun Tanzimat Döneminde taşınamaz eserlerin yerinde korunması olarak görülmeye başlanmış olsa da yöntem ve gereklilikleri günümüzde yeni yeni tartış1maya ve uygulanmaya başlamıştır (Ertosun 2010).

ICOMOS 1990 yılında yayınladığı Arkeolojik Mirasın Korunması ve Yönetilmesi Tüzüğünde, arkeolojik mirasın bütün insanlığın malı olduğunu ve bu nedenle korunması için gereken kaynakların sağlanmasının her ülkenin görevi olduğunu vurgulamıştır(ICOMOS 1990). Arkeolojik mirasın korunmasına yönelik bilimsel davranış başta arkeoloji olmak üzere birçok bilim dalının ortak sorunudur. $\mathrm{Bu}$ ortak çalışma gerekliliği, Venedik Tüzügünde anıtların korunması ve onarımı için mimari mirasın incelenmesine ve korunmasına yardımcı olabilecek bütün bilim ve tekniklerden yararlanılması gerektiği ifadesiyle vurgulanmıştır. Yine Venedik Tüzüğünün 4. Maddesine göre arkeolojik mirasın yerinde korunması ve sergilenmesinin önündeki çözülmesi gereken en büyük problem, koruma ve sergileme amacı ile kullanılacak ürünün veya yöntemin kalıcı ve sürdürülebilir olmasıdır (ICOMOS 1964). Sürdürülebilir olmak için üretilen eserin uzun ömürlü malzemeler içermesi ya da yapıldığı günkü halini koruması yeterli değildir. Yani çözümün değişen iklimsel koşullar, kullanım gereksinimleri ve bürokratik yaklaşımlara karşı kendi bağlamını koruyarak uyum sağlayabilecek esneklikte olması da gerekir. 
Taşınabilir arkeolojik buluntuların çeşitli koruma ve birleştirme teknikleri kullanılarak uzun süreli koruma altına alınmaları mümkündür. Fakat duvar resimleri, mozaikler gibi yerinde korunması ve sergilenmesi daha uygun olan kültür varlıklarının, koruma çalışmalarına rağmen olumsuz hava koşulları ve insanların fiziksel etkisi gibi yollarla zarar görmeleri söz konusudur (Zeren - Uyar 2012). Bu tip anıt eserlerin muhafazası daha farklı koruma çabalarını gerektirir. Farklı niteliklerde koruyucu örtü ve strüktürler önerilen yöntemlerden birisidir. Taşınamaz arkeolojik mirasın korunmasında kullanılacak koruyucu örtü ve strüktürler, bozulma faktörlerine karşı koruma sağlamanın ötesinde araştırma ve sunuma yönelik olanaklar sağlarlar. Taşınır ve/veya taşınamaz eserlerin ortaya çıkarıldığı neredeyse bütün kazılarda, kolay etkilenen ve bozulan malzemenin nemden, ani kurumadan ve mekanik hasarlardan korunması için örtüye ihtiyaç duyulur (Schmidt 1988). Koruyucu yapılar, bozulma faktörleri üzerinde kontrol sağlayan ve sistemin sunumuna izin veren örtülerden biri olarak düşünülebilir. Koruyucu yapıların tasarlanma ölçütleri, yasal yükümlülükler ile kullanılacak teknolojik olanakların kullanımı ve ekonomisi açısından her ülkeye göre değişkenlik göstermektedir.

$\mathrm{Bu}$ çalışma kapsamında mozaik buluntularını doğru mekânsal koşullarda deneyimleyebilmek ve koruyarak aktarabilmek için üretilecek üst örtü ve koruyucu yapıların tasarımları aşamasında mimarlar, arkeologlar ve konservatörler tarafından üzerinde durulması gereken ölçütleri belirleyebilme aşamasında düşünülmesi gereken ilişkiler ve tasarım sürecinde göz önünde bulundurulması önemli olan koşulların altı çizilecektir.

\section{Mozaik Buluntuları için Koruyucu Örtü Tasarlarken Göz Önünde Bulundurulması Gereken Süreçler}

Mozaik kazıları; buluntunun kırılganlığı, uzun süre zemin altında kaldıktan sonra toprak üzerine çıkarıldığında birleştirici malzemenin karşılaşacağ ani değişimlerden etkilenip hasar görme olasılığı ve açmalar ile alandaki hareketliliğin zeminde ani çökmeler ve kaymalar oluşturup buluntuya zarar verme ihtimali gibi risklerden dolayı özellikle dikkat ve özen gerektiren çalışmalardır. $\mathrm{Bu}$ hassasiyet gereksinimi hem kazı çalışmaları hem de sonrasındaki sergileme sürecinde yapılacak koruyucu örtülerin de tasarımını yakından ilgilendirmekte ve tasarımcının karşısına çözülmesi gereken bir problem olarak çıkmaktadır.

Mozaikleri korumak ve sergilemek amaciyla tasarlanacak olan koruyucu örtü ve strüktürlerin duyarlı olması gereken iki farklı süreç vardır. Bunlardan ilki kazıların ve araştırmaların devam ettiği "Araştırma Süreci” dir. Bu süreç bakanlığın kazıya izin verdiği sezonlar ve buluntuların henüz sergilemeye açılmasının uygun olmadığı ve araştırmaların devam edemediği sezon arası zamanlardır. Araştırma sürecinde koruyucu elemanların karşılık vermeleri gereken korumaya yönelik ihtiyaçlar da değişkenlik gösterir.

Araştırma sürecinde ortaya çıkan mozaiklerde yapılan koruma uygulamaları, önleyici uygulamalar ve etkin koruma uygulamaları olarak sınıflandırılmıştır (Şener 2012). Önleyici koruma uygulamaları buluntunun ortaya çıkartılmasından ince temizlik aşamasına gelene kadar geçen süreçte gereken uygulamalardır ve bu uygulamalar daha çok iklimsel koşulların buluntu ve kazıda çalışanlar için idealize edilmesine gereksinim duyar. Öncelikle mozaiğin yeni bir ortamla karşılaştığında zarar görmemesi, ardından da kazıda çalışan araştırmacılar ve destek elemanlarına verimli çalışabilmeleri için ideal ortamın sağlanması amacıyla düşünülmesi gereken, örtünün ani hava değişimlerine karşı koruyucu 
olması ve çalışan kişilerin buluntulara zarar vermeden hareket etmeleri ile kazıda kullanılan araç gerecin hızlı ve güvenli bir şekilde ulaştırılmasına olanak sağlayacak zemin elemanı ihtiyacına karşıllk vermesi gerekmektedir. Mozaik buluntuları mimari buluntulara nazaran daha ince ve özenli çalışma gerektirdiğinden, buluntuların korunabilmesi için toprak çökmelerine, ani 1S1 değişimlerinde ve zemin suyuna yönelik önlemler alınması gerekmektedir (French 1987).

Etkin koruma uygulamaları ise mozaiğin incelendiği, temizlendiği, belgelendiği ve iyileştirilerek araştırmalar ve sergilenmesi için hazırlanması sürecinde yapılan uygulamalardır. Bu uygulamalar hem buluntu için hem de araştırmacılar için daha detaylı mekânsal ihtiyaçlara cevap verilmesine gereksinim duymaktadırlar. $\mathrm{Bu}$ sürece yönelik olarak tasarlanacak olan mimari elemanın taşınabilir buluntuların saklanması ve temizlenmesi için güvenli alanlara, mozaiklerin tortu, bitki kökleri ve eski harçlardan temizlenmesi için olanak sağlayacak nitelikte sirkülasyon aksları ve temizleme sürecinin gerektirdiği araçları saklamak için hacimler içermesi, belgeleme çalışmaları için olanak sağlayacak nitelikte olması gerekmektedir.

Araştırma süreci boyunca alanda çalışacak arkeolog ve araştırmacılara hizmet etmek üzere dinlenme alanları, sslak hacimler ve istendiği takdirde konaklama birimlerinin de tasarlanacak mimari elemanın bir parçası olarak düşünülmesi gerekmektedir. Kazı çalışmaları bilimsel araştırmalar olmakla beraber aynı zamanda eğitim alanı olma işlevi de taşırlar. Bu nedenle tasarlanan elemanın farklı tipte eğitimlere cevap verebilecek nitelikte olması da önemlidir.

Genelde araştırma sürecinde kullanılan koruyucu örtüler geçici olarak tasarlanmaktadır. Fakat bu durum günümüz teknolojileri ve sürdürülebilirlik kavramının gereklilikleri ile birlikte değerlendirilip değiştirilmesi gereken bir durumdur. Sürecin ikinci aşaması olan sezon arası dönemlerde de buluntuların değişken hava koşulları ya da insan eliyle verilebilecek zararlardan korunabilmesi için örtünün mozaiği tamamen örtecek ve dışarıdan erişimi engelleyerek koruma için ideal, sabit hava şartları oluşturan ve insan erişimini tamamen engelleyecek biçimde tasarlanması uygun olacaktır.

Koruyucu örtü veya yapının duyarlı olması gereken ikinci süreç "Sergileme Süreci"dir. $\mathrm{Bu}$ süreç, mozaiğin kazılarla ortaya çıkarılıp temizlik ve belgelenmesinin tamamlanmasının ardından, insan deneyimine açıldığı süreçtir. $\mathrm{Bu}$ aşamada tasarlanan örtünün artık sadece koruyucu olmak ve ideal şartları sağlamaktan farklı ihtiyaçlara da cevap verebilecek nitelikte bir forma dönüşmesi gerekmektedir. Bu aşama artık örtünün kalıcı formuna ulaştığı ve yeni buluntular ve farklı deneyim önermeleri olmadan değiştirilmesinin zorlaştığı aşamadır.

Sergileme süreci için yapılacak tasarımlara yönelik birçok farklı tüzük ve yönetmelik bulunmaktadır. Bunlardan önde geleni olan Venedik Tüzüğü (1964) arkeolojik peyzajlara yapılacak eklemelerle ilgili olarak; yapılacak eklemelerin mevcut dokudan ayırt edilebilir nitelikte, modern yapılar olmaları ve ancak çevreleriyle beraber buluntulara zarar vermediği durumlarda yapılmalarına izin verilmesi gerektiğinin altını çizmektedir.

Arkeolojik peyzajlar farklı mekânsal ölçeklerde yaşayan insanların farklı eylemleri ile şekillenen oluşumlardır (Tuna 2016). İçindeki buluntuların korunması kadar peyzajın da korunması geçmişi anlamak için büyük önem taşımaktadır. Dolayısıyla arkeolojik peyzajların kültürel ve tarihi değeri üzerlerinde yer alacak koruyucu örtü ve strüktürlerin tasarımlarına yönelik ölçütler belirlenmesi için farklı yaklaşımlar içeren birçok araştırmanın yapılması 
kaçınılmaz ihtiyaçtır. Araştırmalar sonucunda belirlenen ölçütler arasında arkeolojik peyzaj üzerinde tasarlanacak örtülerin; buluntuları çevre ve iklim koşullarına karşı koruyan, bozulmaya neden olacak etkenleri en aza indiren, yeni bozucu etkenlere neden olmayan, buluntuları öne çıaran, çevre ile uyumlu, dönüştürülebilen, kaldırılabilen ve kalıntılara zarar vermeyen yapılar olması gerektiği fikirleri öne çıkmıştır (Zeren - Uyar 2010; Ertosun 2012; Yılmaz vd. 2019). Ayrıca kazı alanı ölçeğinde öncelikle alanın drenajının sağlanması yoluyla su döngüsünün kontrol altına alınması, araştırma ve izlemeye yönelik erişimdolaşım hattı oluşturulması, ani çevresel değişimlerin etkilerini azaltmak ve insan kaynaklı tehditlere karşı buluntuları korumak için güvenlik önlemlerinin alınması ile buluntunun sunumu ve yorumlanmasına katkıda bulunacak önerilerde bulunmak (Ertosun 2012) da önerilen ölçütler arasındadır.

\section{Mozaik- Koruyucu Örtü ve Mekânsal Deneyim İlişkisinin Tasarımda Yönlendirici Rolü}

Mimari tasarım; tasarlanacak mekân, mekânın içeriği, mekânı kullanacak kişiler ve mekânın yaratması istenen etki gibi birçok farklı değişkenin aralarındaki ilişkiler ile yönlenen karmaşık bir süreçtir. Zamanın sürekliliği içinde mimar, geçmişi geleceğe bağlamak yoluyla uygun bir yaşam ve çevre oluşturabilir. Bunu başarmak içinse geçmişi ve şimdiyi anlamak zorundadır (Thiry 1959). Tasarlanan şeyin varoluşunu anlamak için onu oluşturan, etkileyen ve ondan etkilenen aktörler arasındaki ilişkileri anlamak önemlidir. Çünkü bu ilişkileri anlamak yapılacak tasarımın daha nitelikli, kalıcı ve sürdürülebilir olmasına olanak sağlar.

Tasarlanacak mekâna yönelik farklı aktörler arasındaki ilişkilerin çözümlenmesi yoluyla tasarımla ilgili belirleyici veriler elde edilebilir. Çalışma kapsamında gereksinimlerini belirlemeyi amaçladığımız mozaiklere tasarlanacak koruyucu örtülerin tasarımı için kullanılacağı süreçlere yönelik ihtiyaç programlarının belirlenmesinin ardından, korunması ve sergilenmesi için tasarlandığı mozaikler ile koruma ve sergileme amacı taşıyan koruyucu örtüler ve mozaiği görmeye gelen kişilerin yaşamaları istenen mekânsal deneyimin arasındaki ilişki çözümlenmiştir.

Burada bahsedilen ilişkisel çözümleme, J. G. Bennett'ın 1956 yılında araştırılan fenomenin bütüncül anlamını anlayabilmek için tasarladığı Basit Sistematik modelinin ilişkisel anlamı kavrayabilmek için kurgulanmış triad aşamasının uygulanması yoluyla yapılmıştır. Triad herhangi bir fenomenin dinamik bileşenleri arasındaki ilişkileri anlayarak fenomenin doğasını anlamayı hedefler (Bennett 1993). İlişkisel anlamın tasarlanacak mimari elemanlar için tasarım aşamasında uygulanması, elemanın doğru kurgulanmasına imkân vererek onun daha kalıcı ve sürdürülebilir olmasına olanak sağlar. 


\begin{tabular}{|c|c|c|c|}
\hline & Etki & İlişkisel Çözümleme & Çıktı \\
\hline $\begin{array}{l}\text { İlerleme } \\
\text { Örtü-Mozaik-Deneyim }\end{array}$ & $\begin{array}{l}\text { Destekleme, } \\
\text { Güçlendirme }\end{array}$ & $\begin{array}{l}\text { Örtü buluntunun deneyimleyende yaratması istenen deneyime göre } \\
\text { biçimlenir. }\end{array}$ & Şekillenme \\
\hline $\begin{array}{l}\text { Etkileşim } \\
\text { Örtü- Deneyim-Mozaik }\end{array}$ & $\begin{array}{l}\text { Anımsama Deneyimi, } \\
\text { Tarih Deneyimi }\end{array}$ & Örtünün formu ve kurgusu buluntunun değerini aktarmada rol oynar. & Mekânsal Deneyim \\
\hline $\begin{array}{l}\text { Kimlik } \\
\text { Mozaik-Deneyim-Örtü }\end{array}$ & Kişiselleştirme & $\begin{array}{l}\text { Ziyaretçiler mozaiğin anımsatma değeri ve örtü ile desteklenen mekânsal } \\
\text { deneyim yoluyla arkeolojik alanı kişiselleştirirler. }\end{array}$ & $\begin{array}{l}\text { Arkeolojik peyzaj1 } \\
\text { anlamak }\end{array}$ \\
\hline $\begin{array}{l}\text { Düzen } \\
\text { Deneyim-Örtü-Mozaik }\end{array}$ & Bağlilik & $\begin{array}{l}\text { Deneyimleyenlerin (araştırmacı, ziyaretçi) örtü ile desteklenen ören } \\
\text { yerine olan bağlılığının artması. }\end{array}$ & $\begin{array}{l}\text { Ziyaret ve yeniden } \\
\text { ziyaret sayısında } \\
\text { artış }\end{array}$ \\
\hline $\begin{array}{l}\text { Özgürlük } \\
\text { Deneyim-Mozaik-Örtü }\end{array}$ & Yenilenme, Devinim & $\begin{array}{l}\text { Ziyaretçi sayısının artması ekonomik getiriyi arttırır, alana kendine ait bir } \\
\text { gelir akışı oluşturur. }\end{array}$ & Güçlenme \\
\hline
\end{tabular}

Mozaiğin sahip olduğu sanat ve mesaj içeriğinin örtünün formunu biçimlendiren önemli etkenlerden biri olduğu söylenebilir. Mozaik ile örtünün birbirlerini destekleyen şekilde tasarlanması örtüyü bağlamsal olarak kuvvetlendirirken, mozaiği ön plana çıkararak değerini aktarabilmesi için de destekleyici rol oynar. $\mathrm{Bu}$ karşılıklı fayda durumu mekânsal deneyim yoluyla, mozaiğin tarihi ve anımsatma değerini öne çıkararak örtünün kullanım değerini de arttırır.

Örtünün sergilenen mozaiğe göre biçimlenmesi onu benzerlerinden farklı k1lar ve mekânsal deneyimi özgünleştirir. Yere ait özgün deneyim ve tasarımın üzerine uygulandığı arkeolojik peyzaja uygunluğu da alanın ziyaretçi tarafından bütüncül olarak anlaşılmasını kolaylaştırır. Kolay anlaşılan mekanlar kişilerin kendilerini o mekânda güvende hissetmelerini sağlar. Kişiler güvende oldukları yerlerde daha çok zaman geçirmeye ve o mekanlara yeniden gelmeye yatkınlık göstermektedirler.

Bilinirliğin artması ziyaret sayısını arttırır, artan ziyaretçi sayısı arkeolojik peyzajın bulunduğu yerleşimde turizm altyapısının sağlanması ya da varsa güçlendirilmesi ihtiyacını doğurmakta ve bölgesel bir gelir kaynağı oluşturmaktadır.

\section{Sonuç}

Yerinde korunması planlanan mozaiklerin korunması ve sergilenmesi ihtiyacina karşılık vermek için tasarlanacak mimari ve endüstriyel elemanların sahip olması gereken nitelikleri belirlerken, incelenmesi ve anlaşılması gereken üç temel ilişki vardır. Bunlar sergilenen ve korunan elemanın; insanla, iklimsel koşullarla ve bilimsel araştırmalara sağlanacak olan olanaklarla olan ilişkileridir. İnsanla olan ilişkiyle ilgili olarak, mozaiğin insan hareketi ve fiziksel temasından korunması ve bu korumayı gerçekleştirirken görsel ilişkinin kesintisiz olarak sağlanması gerekmektedir. Sergi elemanlarının görsel ilişkiyi sağlamanın ötesinde, deneyimi tamamlamak için sergilenen eser ile ilgili gerekli bilgiyi hem işitsel hem görsel ve mümkünse farklı duyulara hitap edecek biçimde sağlanması ideal olur. İklimsel koşullarla olan ilişkide birden çok bileşen düşünülmelidir. Öncelikle mozaiğin korunması için ideal 1sı1, 1şık ve akustik koşullarının sağlanması gerekir. Bu koşulların korunan eser için olduğu kadar, deneyimleyen insan ve araştırma yapan bilim insanları için de değiştirilebilir ve
Tablo 1

Örtü-Mozaik-Mekânsal Deneyim İlişkisi Çözümlemesi. 
ideal hale getirilebilir olması uygun olur. Mimari elemanın izleyicilere kontrollü görsel ve fiziksel erişim sağlarken, bilimsel araştırmalar sürecinde daha fazla erişim ve müdahaleye olanak sağlayacak şekilde esnek tasarlanması önemlidir.

Ayrıca tasarlanan mimari elemanın parçası olduğu çevre ile uyum içerisinde olması lazımdır. Bunu sağlayabilmek için izlenecek yollardan biri; tasarlandığı yerin etnik malzeme ve iklimlendirme çözümlerini, tasarımın bir parçası olacak şekilde yeniden yorumlayarak kullanmak olabilir. Bu çevreye duyarlı ve saygılı tasarım yaklaşımı 1994 yılında Japonya'da hazırlanan Nara Özgünlük Belgesinin vurguladığı; "Bir anıtın ya da sitin doğasına ve kültürel bağlamına bağll olarak; özgünlük yargısı çok çeşitli bilgi kaynaklarına bağlıdır. Bu kaynaklar; tasarım ve biçimi, malzeme ve nesneyi, kullanım ve işlevi, gelenek ve teknikleri, konum ve yerleşimi, ruh ve anlatımı, ilk tasarım ve tarihsel evrimi içerir. Bilgi kaynakları yapıtın bünyesinde olabileceği gibi, dışında da olabilir. Bu kaynakların kullanımı kültür mirasının, sanatsal, teknik, tarihsel ve toplumsal boyutlarıyla tanımlanmasına olanak verir." yaklaşımı ile kavramsal olarak uyumludur (Asatekin 2004: 82-85).

Günümüz iklimsel sorunları düşünüldüğünde, sergi elemanının çevreci ve sürdürülebilir olması eskiye nazaran çok daha önemli hale gelmiştir. Değişen koşullara uyum sağlayabilecek ve değiştirilmeye, yeniden şekillendirilmeye olanak sağlayacak esneklikte tasarımlar, varlıklarını daha uzun sürdürürler. Ayrıca mimari eleman yeterli gelmediğinde genişleyebilecek, gerekliliğini kaybettiğinde çevresine zarar vermeden kaldırılabilecek ve başka bir alanda yeniden kullanılabilecek nitelikte olmalıdır.

Mozaiklerin korunması ve sergilenmesine yönelik olarak tasarlanacak örtülerin uyması gereken tasarım ölçütlerini dikkate alarak tasarlanacak, alan ve korunacak elemanlarla ilgili farklı ilişkiler ile gereksinimleri çözümleyerek belirlenecek stratejiler yoluyla nitelikli ve uzun süre değiştirilmeden kullanılabilecek eserler oluşturmak mümkündür. İncelenecek ilişkiler ne kadar çeşitlendirilirse, belirlenecek stratejiler o kadar çok probleme çözüm sunabilir. Bu çözümlemeler yoluyla sadece tasarıma yönelik değil koruma ve geliştirme yöntemlerine yönelik veriler de elde etmek mümkündür. 


\section{Kaynaklar - Bibliography}

Asatekin 2004

Bennett 1993

Ertosun 2012

French 1987

ICOMOS 1964

ICOMOS 1990

Reigl 2015

Rizzi 2007

Schmidt 1988

Șener 2012

Thiry 1959

Tuna 2016

Y1lmaz vd. 2019

Zeren - Uyar 2010
N. G. Asatekin, Kültür ve Doğa Varlıklarımız Neyi, Niçin, Nasıl Korumalıyız?, Ankara.

J. G. Bennett, Elementary Systematics; A Tool for Understanding Wholes, Santa Fe.

A. I. Ertosun, Evaluation of protective structures in archaeological sites for in situ conservation of architectural remains and artifacts, Yayınlanmamış Yüksek Lisans Tezi, Orta Doğu Teknik Üniversitesi, Ankara.

P. French, "The Problems of In situ Conservation of Mudbrick and Mud Plaster", W. M. Henry - M. A. Corzo (eds.), In situ Archaeological Conservation: Proceedings of Meetings, Mexico, 78-83.

“Venedik Tüzüğ̈̈”, http://www.icomos.org.tr/Dosyalar/ICOMOSTR tr0243603001536681730.pdf, (10.04.2020).

“Arkeolojik Mirasın Korunması ve Yönetilmesi Tüzüğü”, http://www.icomos.org.tr/Dosyalar/ICOMOSTR tr0574229001536913919.pdf, (10.04.2020).

A. Reigl, Modern Anıt Kültü Doğası ve Kökeni, İstanbul.

G. Rizzi, "Preface”, J. Ashurst (ed.), Conservation of Ruins, xviii-xxiii, Oxford.

H. Schmidt, Schutzbauten, Stuttgart.

Y. S. Şener, “Arkeolojik Alanda In Situ (Yerinde) Mozaik Koruma Yöntemleri”, JMR 5, 201-220.

P. Thiry, “Total Design”, Journal of American Institute of Architects 32, 19-28.

A. Tuna, “Arkeolojik Peyzajların Sunumunda Kullanılan Yapısal Unsurların İrdelenmesi”, İnönü Üniversitesi Sanat ve Tasarım Dergisi 6, 13, 131-146.

M. Yılmaz - Y. S. Şener - A. Bakıroğlu Yılmaz, “Arkeolojik alanlarda Uygulanan Koruma Örtülerinin Tasarım Kriterleri”, STD 23, 413-429.

M. T. Zeren - O. Uyar, "Arkeolojik Alanlarda Koruma Çatıları ve Gezin Platformlarının Düzenlenmesi Kriterleri”, Dokuz Eylül Üniversitesi Mühendislik Fakültesi Mühendislik Bilimleri Dergisi 12, 2, 55-64. 